\title{
Methods of mathematical modeling and urban space organization
}

Irina Mayatskaya*, and Batyr Yazyev

Don State Technical University, 344022, Rostov-on-Don, Russia

\begin{abstract}
The use of digital technologies and methods of mathematical modeling allows modern architects to design the cities that have their own unique style and harmoniously fit into the environment. It is necessary to widely introduce three-dimensional modeling methods into practice for more effective urban space creation and development.
\end{abstract}

\section{Introduction}

The architecture and the very space of a modern city are very diverse, have a variety of development directions, characteristic of this particular urban environment [1-4]. With the development of digital technologies, it is possible to create unique urban spaces using the methods of fractal geometry and the methods of graph theory $[5,6]$.

It is only necessary to understand these patterns of urban architectural appearance development and the organization of space, traditions and history of the city (Fig. 1, 2).

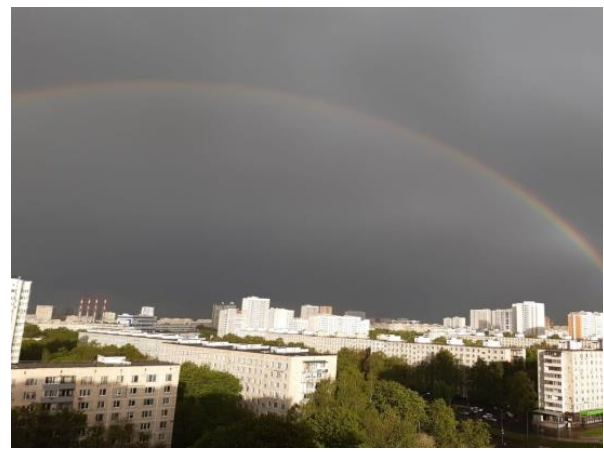

Fig. 1. The architectural appearance of a modern city.

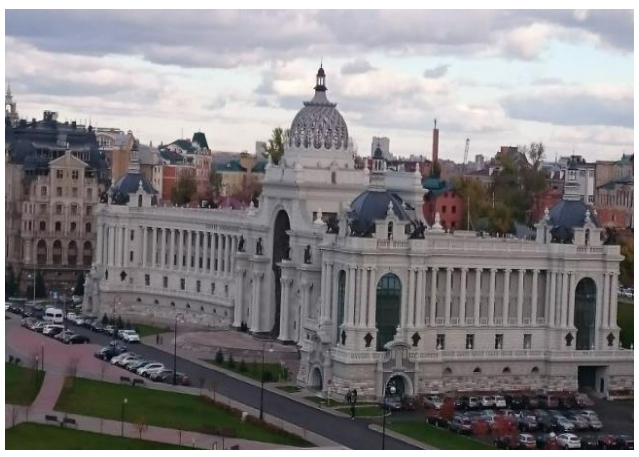

Fig. 2. The historic center of the modern city.

3D modeling is a unique technology behind which the future of architectural projects lies, which has the ability to create unique complexes of structures and the architectural appearance of cities. Three-dimensional modeling is a process of forming computer models that gives a possibility to make the real dimensions, shape, appearance of an object and its other characteristics with maximum accuracy. This allows us to analyze the model taking

\footnotetext{
*Corresponding author: irina.mayatskaya@mail.ru
} 
into account all the features and further eliminate the shortcomings identified in the process of its creation. Modeling using 3D technologies is a tool for architects, designers in the implementation of their projects.

Mathematical modeling, digital technologies and innovations, three-dimensional modeling methods allow creating digital 3D models for analyzing the development of a city. Modern methods of studying and forecasting the urban space development help creating a comfortable living environment for a person and preserve cultural heritage.

\section{Urban space and graph theory}

Graph theory is an area of discrete mathematics, a feature of which is a geometric approach to the study of objects [6,7]. Historically, the theory of graphs originated in 1736, when the first work of L. Euler in this direction was published. He solved the well-known problem of seven bridges over the Pregolya River in Königsberg (in Kaliningrad). It was he who first received the graphic representation. And only in 1936 the Hungarian mathematician Denesh König wrote a monograph "The theory of finite and infinite graphs" and he is considered the founder of this theory. Nowadays graphs and related research methods permeate modern mathematics. These methods are effectively used in planning and management theory, economics, sociology, biology and medicine, but very few are used in urban planning.

In the urban environment development, a number of problems that are typical for many cities can be identified [8]. The townspeople feel the need to organize such an urban space that allows them to solve the most diverse problems of the city. These include the following problems:

1. Buildings and structures are placed in an order that has an adverse effect on living conditions;

2. The structure of the city hinders the economy development;

3. Narrow streets obstruct traffic;

4. Chaotic development of no architectural value, which adversely affects the general appearance of the historical and architectural sights of the city;

5. Environmental pollution;

6. High building density of the city or its individual parts;

7. Non-observance of storey regulations, especially in the city center;

8. Insufficient number of park areas.

A very important component of the urban space organization is the transport system. The development of transport infrastructure must be predicted in order to avoid mistakes in the design of this system. Methods of mathematical modeling can effectively solve this problem. Namely, the use of graph theory methods can create mathematical models that will make it possible to build transport networks, take into account the flow rate of cars and regulate the system of passing cars using traffic lights (Fig.3, 4).

The use of graph models allows us to solve the problem of optimizing traffic flow in an urban structure. The complexity of constructing an optimized tree of the graph-model can be overcome by using computer technologies [7]. When constructing, it is possible to use plane graphs, the vertices of which are points on the plane, and the edges are continuous lines without self-intersections connecting the corresponding vertices (Fig. 5). These vertices are connected by lines so that the two edges have no common points other than these vertices. Trees represent an undirected connected graph without cycles (Fig. 6) [6-9]. 


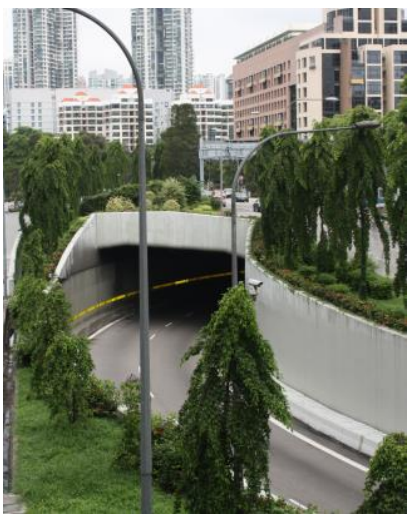

Fig. 3. Tunnel as a part of the city's transport network.

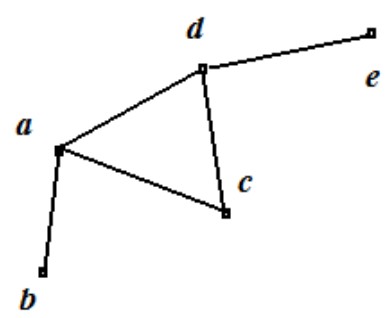

Fig. 5. Plane graph.

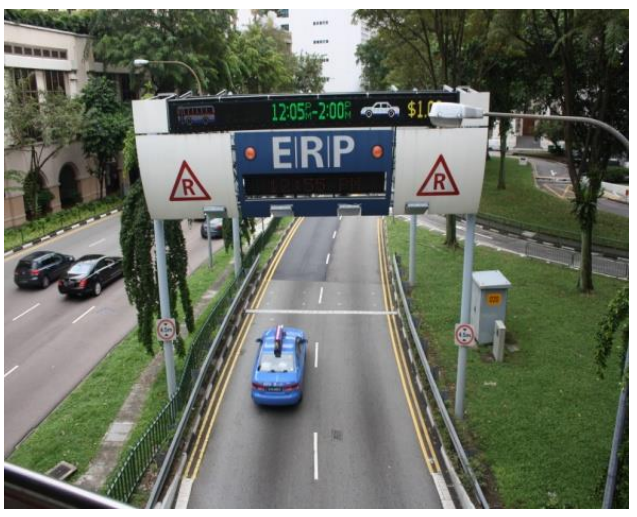

Fig. 4. Transport network of a modern city.

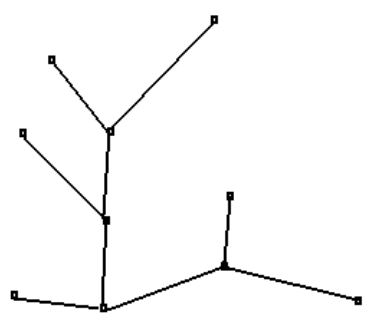

Fig. 6. The tree as part of the graph model.

This theory is well studied by the mathematicians who are engaged in discrete mathematics, and is widely used in programming. But in construction and in the development of urban planning, this modern computer technology is insufficiently used in solving emerging problems.

Fig. 7 shows directed graphs. It is the theory of networks, which is a branch of graph theory, that is suitable for the mathematical description of the city's transport network. A network is a directed graph with a weighting function and selected vertices. The examples of this construction are the graph-model of plant objects. When simulating, it is possible to decrease or increase the flow in the network so that the traffic flow does not exceed the capacity of the system. In the case of finding the maximum flow, the Ford-Fulkerson algorithm [6] can be used.
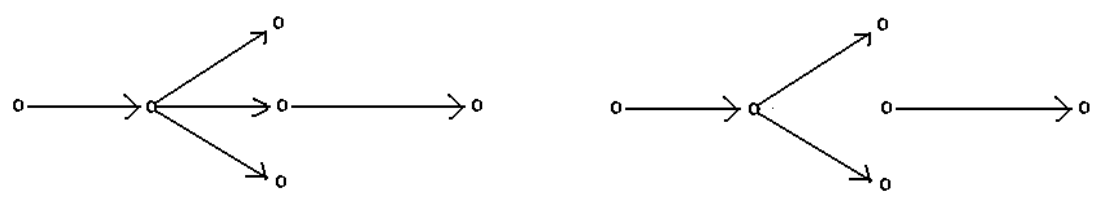

Fig. 7. Directed graphs.

Situations arise when not all paths on the graph are admissible, and then it is impossible to directly apply classical algorithms of graph theory. Mathematicians began to conduct research in this direction, developing the theory of dynamic graphs with non-standard attainability. 


\section{Urban space and fractal theory}

In an urban environment, the organization of both external and internal space is very important. The architecture of the city is closely related to human life. Digital technologies and the pace of life give new trends in the city architectural appearance development. It has become more dynamic and more complex in spatial structures [10-15]. This dictates the use of new technologies for designing the buildings themselves and organizing the space around them and in interaction with already built structures. BIM technologies and methods of mathematical modeling based on the theory of fractals and the theory of graphs help to cope with these trends.

Urban space is a spatial multifractal of the stochastic type [10]. The spatial fractality of the city is the result of its development from the beginning of the construction of buildings in it to the modern architectural appearance, taking into account the historical heritage (Fig. $8,9)$.

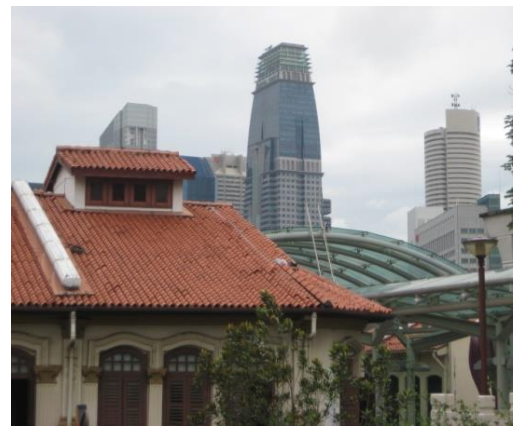

Fig. 8. The architectural appearance of the city with historical buildings.

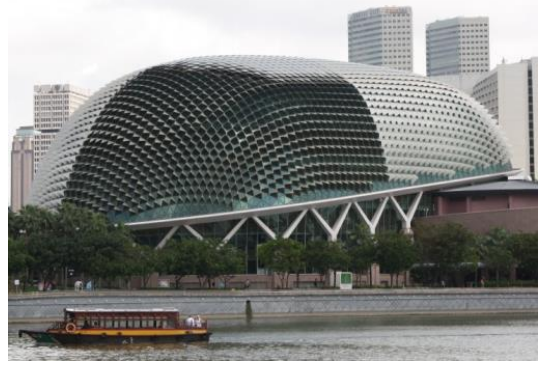

Fig. 9. The architectural appearance of the city with modern buildings.

One of the tendencies is the orientation of urban architecture towards the study of the natural objects' development patterns, their use in the structures design and the environmental problems' solution. Currently, architects are paying more and more attention to architectural bionics and "green" architecture [16-18]. The search for the organic existence of nature and the construction of structures complexes are one of the important trends in urban space development.

With the digital technologies' development, it is possible to create unique urban spaces using fractal structures. The use of special computer programs, for example, Fractal Explorer, Apophysis, gives an opportunity to look differently at the space itself and shaping. In fractal architecture, architects introduce irrational forms and fractional dimension, stochasticity of objects. This makes it possile to create modern structures that surprise with their shape, structure and organization of space (Fig. 10-12).
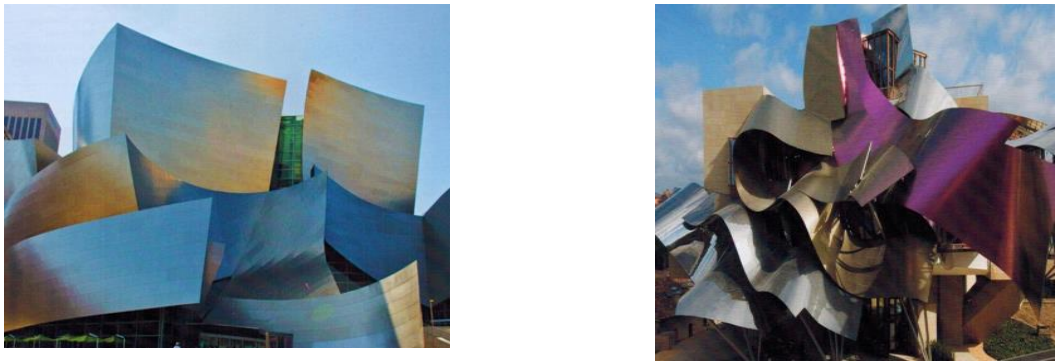

Fig. 10. Modern structures with a complex surface. 


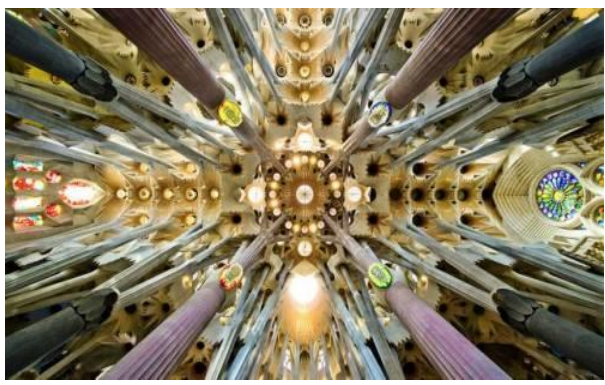

Fig. 11. Fractal elements of the interior space of the Sagrada Familia in Barcelona.

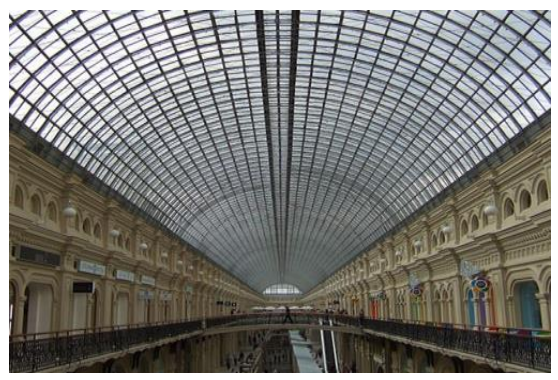

Fig. 12. Fractality of the internal space of GUM in Moscow.

To set a fractal structure means to set the principle of development, the law of changing the form, the very organization of an object $[19,20]$. Fractals in the urban space create a holistic look, which ensures the unification of objects, the interaction of which ensures the development of subsequent trends in connection with the previous one. Fractals, constantly changing, are able to create new forms within a given structure.

The use of the fractal principle in the architectural shaping process makes it possible to combine the irrational and the rational. It is possible to apply the methods of mathematical forecasting in the city architectural appearance development. The fractal method is an effective way of organizing space. It is used as a method of analysis, a way of designing and modeling architectural forms. This makes it possible to create complexes of structures that have harmonious, symmetrical and asymmetrical, dynamic and self-similar forms.

The use of the laws of nature in the architectural forms' shaping made it possible to create historical structures with a fractal structure. And in the future, such an architectural direction as architectural bionics was developed. Intuitive fractality is present in many historical architectural monuments. Currently, such architects as Antoni Gaudi, Zaha Hadid, Santiago Calatrava, Frank Gehry, Frank Lloyd Wright, Renzo Piano have created simply unique buildings built using the fractal principle of shaping (Fig. 13-17). This manifests itself both in the outer space of the structure and in the inner space.

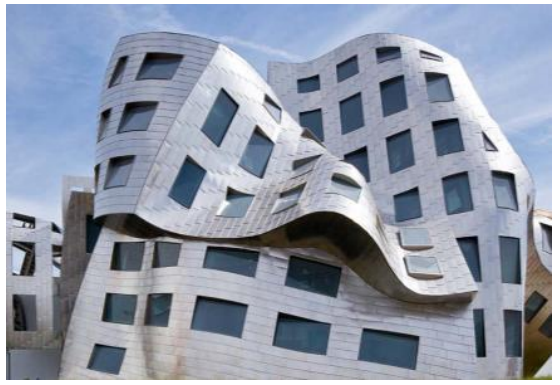

Fig. 13. Lou Ruvo Center for Brain Health (architect Frank Gehry).

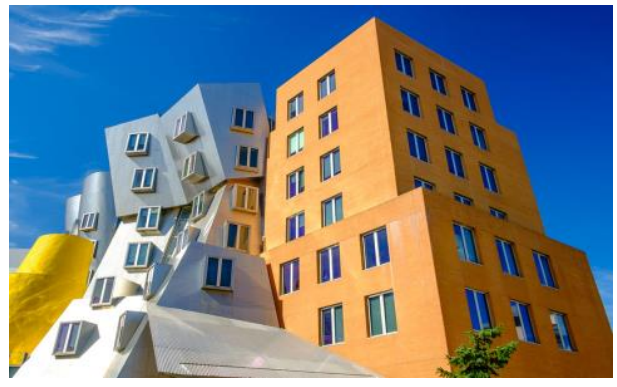

Fig. 14. Ray and Maria Stata Center (architect Frank Gehry). 

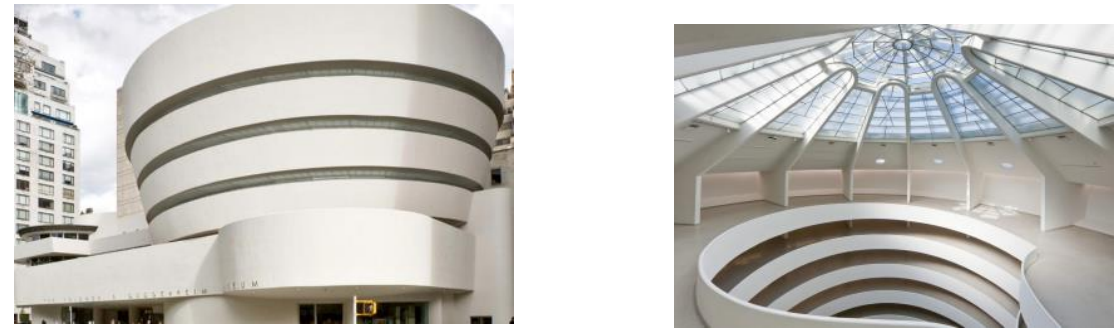

Fig. 15. Solomon Guggenheim museum (architect Frank Lloyd Wright).

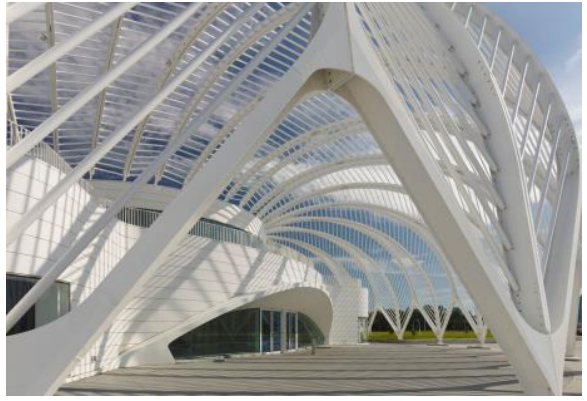

Fig. 16. Florida Polytechnic University (architect Santiago Calatrava).

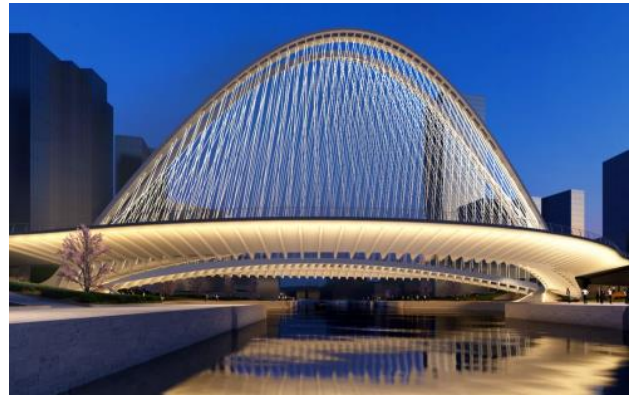

Fig. 17. Gallery of Santiago Calatrava.

Shear, bending, fracture of surfaces, traces of movement - these elements, when designing unique structures, create an integral object (Fig. 18, 19). Nowadays, the curved surfaces are much more commonly used in project creation than the rectilinear shapes. Complexity in shaping leads to a new perception of reality. The complex external shape is reflected in the complex structure of the building itself. Further, it is necessary to ensure the unity of this building and the architectural appearance of the city. Digital technologies and modern software systems help to analyze the organization of urban space.

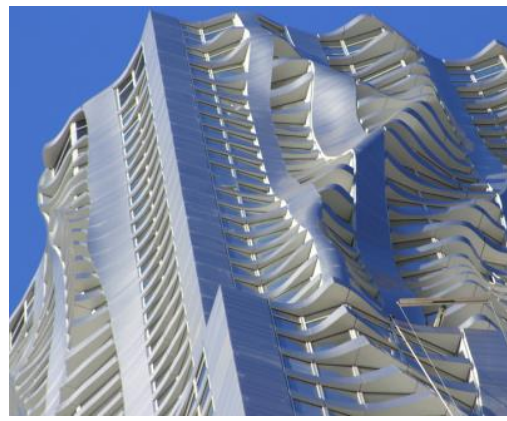

Fig. 18. The 76-story skyscraper in Lower Manhattan, New York (architect Frank Gehry).

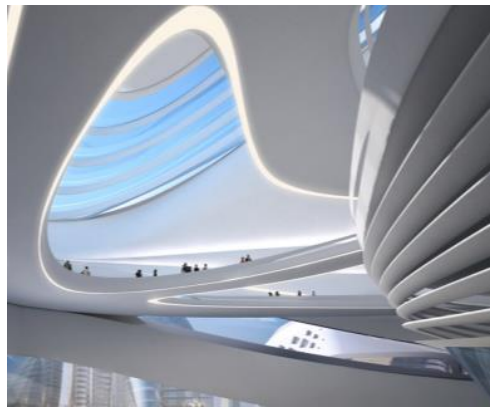

Fig. 19. Amazing surfaces (architect Zaha Hadid).

Mathematical modeling, using algorithms for architectural shaping, makes it possible to study the patterns of urban space development and organization. It should be noted that the analysis should be carried out taking into account natural objects located both inside the city and outside it. The analysis itself makes it possible to compare a fairly large number of variants of the city development. It is necessary to further develop the methods of architectural shaping based on fractal geometry and nonlinear dynamics. 


\section{Conclusion}

Due to the new construction technologies development and the emergence of new building materials, it became possible to create a wide variety of forms in the structure of both external and internal space. Architects have created and continue to design the unique structures of fractal architecture.

Fractal geometry methods and modern software systems are helpful in finding the architectural elements most amazing in form and original in structure. It was the development of fractal architecture that made it possible to create a unique city image. In the modern world, cities should have the features inherent only in this city, and then a person will also be able to live comfortably in it.

\section{References}

1. V.A. Kolyasnikov, Modern theory and practice of urban planning: territorial urban planning, (Architecton Publishing, Yekaterinburg, 2010).

2. H. Stierlin, Encyclopaedia of world architecture (Evergreen Publishing, 1994).

3. V.P. Maksakovsky, World cultural heritage (Piter Publishing, 2002).

4. P.P. Gnedich, World architecture (Publishing house Eksmo-Press, 2012).

5. B. Mandelbrot, Fractal geometry of nature, (Publishing Institute for Computer Research, 2002).

6. J.A. Anderson, Discrete mathematics and combinatorics (Publishing Williams, 2003).

7. V.N. Kasyanov, V.A. Evstigneev, Graphs in programming: processing, visualization and application (BHV-Petersburg Publishing, 2003).

8. I.A. Mayatskaya, I.A. Krasnobaev, Engineering Journal of Don 4-2(23), 158 (2012).

9. I.A. Mayatskaya, Bulletin of the Don State Technical University 5(27), 706-711 (2005).

10. M. Batty, P. Longley, Fractal Cities: a geometry of form and function (Publishing Academic Press, San Diego, 1994).

11. I.A. Mayatskaya, S.B. Yazyeva, B.M. Yazyev, Construction and industrial 12 (64), 2932 (2018).

12. B.M. Yazyev, I.A. Mayatskaya, S.B. Yazyeva, S.B. Yazyev, Materials Science and Engineering 698 (2), 022087 (2019).

13. I.A. Mayatskaya, B.M. Yazyev, S.B. Yazyeva, Construction and architecture 9, 1(30), 66-70 (2021).

14. S.B. Yazyeva, I.A. Mayatskaya, I.V. Kashina, A.N. Nesterova, Materials Science and Engineering 698 (3)), 033046 (2019).

15. I.A. Mayatskaya, B.M. Yazyev, S.B. Yazyeva, Materials Science and Engineering 1083, 0012028 (2021).

16. I.A. Mayatskaya, B.M. Yazyev, S.B. Yazyeva, P.B. Kulinich, MATEC Web of Conference 01031 (2017).

17. I.A. Mayatskaya, V.D. Eremin, S.B. Yazyeva, Construction and architecture 7 (1), 9196 (2019).

18. S.B. Yazyeva, I.A. Mayatskaya, Materials Science and Engineering 1083, 0012018 (2021). 
19. I.A. Mayatskaya, V.D. Eremin, B.M. Yazyev, Construction and architecture 9, 1(30)), 76-80 (2021).

20. R. Cronover, Fractals and chaos in dynamical systems (Publishing Technosphere, 2006). 